\title{
ANALISIS PENURUNAN PADA TIMBUNAN DENGAN PREFABRICATED VERTICAL DRAIN (PVD) MENGGUNAKAN DATA HASIL UJI CPTu
}

\author{
Tomy Gunawan', Alfred Jonathan S., dan Ali Iskandar ${ }^{3}$ \\ ${ }^{1}$ Program Studi Sarjana Teknik Sipil, Universitas Tarumanagara, Jl. Letjen S. Parman No.1 Jakarta \\ tomygunawan26@gmail.com \\ ${ }^{2}$ Program Studi Sarjana Teknik Sipil, Universitas Tarumanagara, Jl. Letjen S. Parman No.1 Jakarta \\ alfred@ft.untar.ac.id \\ ${ }^{3}$ Program Studi Sarjana Teknik Sipil, Universitas Tarumanagara, Jl. Letjen S. Parman No.1 Jakarta \\ ali.iskandar1999@gmail.com
}

\begin{abstract}
Investigation of soil is important to do in the planning of building construction such as foundations, piles, roads, etc. To find out the bearing capacity and parameters of the soil where a building will be built. Investigation of the soil can be done in various ways, one of which uses an electrical cone penetration test with pore water pressure. In the embankment project for the calculations on the soil so that it can be known about the settlement in soil and the length of time it reaches the hydrostatic level. Cone penetraton test is reqired and the results produce data in the form of cone resistance $\left(q_{c}\right)$, blanket friction $\left(f_{s}\right)$ and pore pressure $(u)$ which will be processed in the CPET-IT program in order to produce soil parameters that will be used for soil settlement analysis. To find out the settlement of embankment soil, it will be supported by finite difference program. Results of studies on general is to find the effectiveness of embankment using prefabricated vertical drain (PVD) and without prefabricated vertical drain (PVD).
\end{abstract}

Keywords: embankment; soil investigation; settlement; CPTu; prefabricated vertical drain

\begin{abstract}
ABSTRAK
Penyelidikan terhadap tanah penting untuk dilakukan pada perencanaan konstruksi bangunan seperti pondasi, timbunan, jalan, dll. Untuk mengetahui daya dukung dan parameter-parameter tanah tempat akan dibangunnya sebuah bangunan Penyelidikan tanah dapat dilakukan dengan berbagai macam cara salah satunya adalah menggunakan uji sondir elektrik dengan tekanan air pori. Pada proyek timbunan memerlukan perhitungan pada tanahnya agar dapat diketahui besarnya penurunan pada tanah dan lama waktu tanah mencapai keadaan hidrostatis. Sehingga dilakukan uji sondir secara elektrik dan dari hasil uji sondir menghasilkan data berupa tahanan konus ( $\mathrm{q}_{\mathrm{c}}$ ), gesekan selimut $\left(\mathrm{f}_{\mathrm{s}}\right)$ dan pore pressure $(\mathrm{u})$ yang akan diolah kedalam program CPET-IT agar menghasilkan parameter-parameter tanah yang akan digunakan untuk analisis penurunan pada tanah.Untuk mengetahui besarnya penurunan pada tanah timbunan maka akan dibantu program berbasis elemen higga. Hasil studi secara umum menunjukkan seberapa besar efektivitas pada timbunan dengan menggunakan prefabricated vertical drain (PVD) dan tanpa prefabricated vertical drain (PVD).
\end{abstract}

Kata kunci: timbunan; penyelidikan tanah; penurunan; $\mathrm{CPTu}$; prefabricated vertical drain

\section{PENDAHULUAN}

\section{Latar belakang}

Di zaman yang selalu berkembang ini, banyak sekali infrastruktur-infrastruktur yang dibangun oleh sebuah negara. Indonesia termasuk salah satu negara yang selalu berkembang dalam pembangunan infrastrukturnya. Setiap pembangunan infrastruktur dibutuhkan penyelidikan terhadap tanah di tempat sebelum infrastruktur dibangun.

Tanah merupakan lapisan teratas bumi yang berasal dari pelapukan batuan dengan bantuan organisme. Tanah terdiri dari partkel-partikel yang tidak saling mengikat sehingga terdapat ruang-ruang yang berisi air dan udara.

Banyak sekali jenis penyelidikan tanah secara in-situ salah satunya adalah CPTu atau Cone penetration test with pore water pressure yang memiliki banyak keuntungan dalam pengaplikasiannya. 
Uji CPTu adalah uji sondir mekanis tetapi uji CPTu dilengkapi instrumen elektrik yang dapat memberikan data lebih baik dari keadaan asli dibandingkan dengan uji sondir mekanis.

Salah satu penggunaan alat ini adalah pada pekerjaan timbunan yang mengalami proses penurunan konsolidasi. Konsolidasi terjadi karena terdisipasinya air pori (pore pressure exces) dari dalam tanah akibat bertambahnya beban, dalam hal ini karena akibat timbunan diatasnya. Proses konsolidasi mengakibatkan terjadinya penurunan elevasi tanah. Proses konsolidasi akan berjalan sampai tekanan air pori mendekati tekanan hidrostatisnya. Proses ini akan berlangsung selama beberapa waktu tergantung jenis tanah dibawahnya. Hal ini menjadi penting karena dalam pembangunan sedapat mungkin settlement yang terjadi tidak membahayakan atau menimbulkan masalah. Sehingga diperlukan analisa dengan metode agar lamanya waktu konsolidasi dapat diperkirakan.Tanah lunak memiliki nilai permeabilitas dan kompresibilitas yang tinggi sehingga penurunan yang akan terjadi akan cukup besar jika menerima beban (Widoanindyawati, 2016). Menurut Rajesh Timbunan merupakan salah satu metode yang cukup efektif dan ekonomis untuk mengurangi penurunan pasca konstruksi dan meningkatkan daya dukung tanah lunak.

Menurut Pasaribu dan Iskandar penimbunan pada tanah lunak dapat dibagi menjadi secara bertahap dan timbunan langsung. Timbunan langsung dapat mengakibatkan tegangan total seketika, yang dapat mengakibatkan kegagalan geser pada tanah. Pada pembebanan bertahap, kekuatan geser akan meningkat secara berangsur-angsur selama proses penambahan beban timbunan.

Semakin berkembangnya teknologi, analisis terhadap uji analisis terhadap penurunan timbunan dapat dilakukan dengan bantuan program-program seperti CPET-IT yang dapat digunakan untuk analisis CPTu dan parameterparameter tanah yang dihasilkan. Selanjutnya menggunakan program analisis penurunan dan konsolidasi yang digunakan untuk mencari besar penurunan timbunan dan lamanya waktu yang diperlukan untuk mencapai keadaan hidrostatis pada timbunan. Estimasi pada penurunan yang dihitung tidak dapat dikatakan akurat, paling tidak besaran penurunan dapat diperkirakan untuk beban, geometri dan jenis tanah adalah setengah atau dua kali dari perkiraan aslinya (Mateos, 2012).

Tes Konsolidasi 1D (oedometer) bertujuan untuk mengevaluasi karakteristik komprebilitas tanah. Pada tanah kohesif dan jenuh, efek beban akan menyebabkan keluarnya air pori, ini lah yang disebut dengan konsolidasi (Mousavi, 2017).

Untuk mempercepat terdisipasinya air pori pada tanah dapat di lakukan perbaikan tanah dengan metode wick drain. Wick drain bertujuan untuk mengurangi laju lintasan pengaliran air dari dalam tanah, yang biasanya digunakan metode Prefebricated vertical drain (PVD).

Pada penelitian ini, penulis akan menganalisa besar penurunan terhadap waktu pada timbunan tanpa menggunakan PVD dan dengan menggunakan PVD yang dibantu dengan program CPET-IT untuk menginpretasikan parameterparameter dari hasil sondir CPTu dan program berbasis metode beda hingga dalam menghitung penurunan.

Penulis akan meneliti tentang besarnya penurunan elastis, konsolidasi dan waktu yang dibutuhkan untuk mencapai keadaaan final consolidation settlement menggunakan data tes uji CPTu.

Agar penelitian ini terfokus pada 1 masalah yang spesifik, batasan-batasan masalahnya berupa data yang dibandingkan dengan hasil dilapangan, data terdiri dari 6 titik uji CPTu, analisis dilakukan dengan metode $1 \mathrm{D}$ konsolidasi coefficient of compressibility, analisis besar penurunan konsolidasi dan waktu menggunakan program analisis penurunan berbasis metode beda hingga, analisis penurunan konsolidasi dilakukan dengan menganggap bahwa tanah mengalami 100\% konsolidasi.

Berdasarkan uraian yang telah dituliskan di atas, masalah perencanaan yang harus diselesaikan yaitu bagaimana menentukan parameter dari hasil uji CPTu menggunakan program CPET-IT, bagaimana mencari besar penurunan elastis, konsolidasi dan waktu hingga mencapai keadaan final consolidation settlement pada timbunan tanpa menggunakan prefebricated vertical drain (PVD), bagaimana mencari besar penurunan elastis, konsolidasi dan waktu hingga mencapai keadaan final consolidation settlement pada timbunan yang menggunakan prefebricated vertical drain (PVD). Mempercepat konsolidasi pada timbunan dapat juga dilakukan dengan menambahkan pompa yang terhubung pada PVD yang disebut dengan metode Vacuum. Menurut Dam et al. (2006), metode ini didasarkan pada gagasan menerapkan pengisapan massa tanah yang terisolasi dengan menggunakan vakum, mengurangi tekanan atmosfir di dalamnya, sehingga dapat mengurangi tekanan air pori pada tanah sehingga tegangan efektif meningkat tanpa mengubah tegangan total.

Tujuan Penelitian Berdasarkan rumusan masalah diatas, maka tujuan dari penelitian ini adalah mengetahui bagaimana cara menentukan parameter dari hasil uji CPTu menggunakan program CPET-IT, mengetahui besar penurunan elastis, konsolidasi dan waktu penurunan waktu hingga mencapai keadaan final consolidation settlement pada timbunan, mengetahui besar penurunan elastis, konsolidasi dan waktu hingga mencapai keadaan final consolidation settlement konsolidasi pada timbunan yang menggunakan prefibricated virtual drain (PVD) 


\section{Coefficient of compressibility $\left(\mathbf{m}_{\mathrm{v}}\right)$}

Modulus yang menggambarkan besarnya perubahan volume tanah seiring dengan berubahnya tegangan efektif tanah (ASTM D2435). Coefficient of compressibility dapat dihitung menggunakan rumus (Robertson, 1997):

$$
\mathrm{m}_{\mathrm{v}}=\frac{k}{\left(C_{v} \cdot \gamma_{\text {water }}\right)}
$$

dengan $\mathrm{mv}=$ coefficient of compressibility, $\mathrm{k}=$ permeabilitas, $\mathrm{C}_{\mathrm{v}}=$ koefisien konsolidasi, $\mathrm{Y}_{\mathrm{water}}=$ Berat isi air

\section{Dimensional constrained modulus (M)}

Constrained modulus merupakan hasil pengukuran tes oedometer. Constrained modulus dapat dihitungan dengan rumus (Robertson, 1997):

$$
M=\frac{1}{m_{v}}=\alpha_{m} q_{t}
$$

\section{Distribusi tegangan}

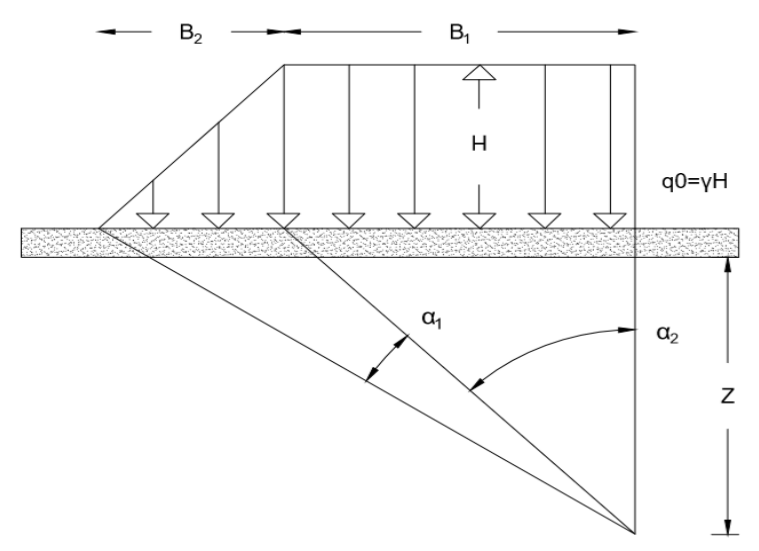

Gambar 1 Distribusi tegangan metode boussinesq

Perhitungan loading stress akibat timbunan dapat dihitung dengan berbagai metode seperti Boussinesq, Westergard, dan 2:1. Perhitungan manual dihitung menggunakan metode Boussinesq (Das Braja, 1995).

Dengan

$$
\Delta \sigma=\frac{q_{0}}{\pi}\left[\left(\frac{B_{1}+B_{2}}{B_{2}}\right)\left(\alpha_{1}+\alpha_{2}\right)-\frac{B_{1}}{B_{2}}\left(\alpha_{2}\right)\right]
$$

$$
\begin{gathered}
q_{0}=\gamma H \\
\alpha_{1}(r a d)=\tan ^{-1}\left(\frac{B_{1}+B_{2}}{z}\right)-\tan ^{-1}\left(\frac{B_{1}}{z}\right) \\
\alpha_{2}(r a d)=\tan ^{-1}\left(\frac{B_{1}}{z}\right)
\end{gathered}
$$

Dengan $\gamma=$ Berat jenis tanah timbunan, $\mathrm{H}=$ Tinggi timbunan, $\mathrm{B}=$ jarak ke titik, $\mathrm{z}=$ kedalaman ke titik, $\alpha=$ sudut ke titik

\section{Penurunan elastis (Immediate settlement)}

Besarnya penurunan elastis dapat dihitung dengan rumus sebagai berikut (Rocscience, 2009)

$$
S_{i}=\frac{\Delta \sigma}{M} H
$$

Dengan $\mathrm{Si}=$ Penurunan elastis, $\sigma=$ Tegangan total, $\mathrm{M}=$ Constrained modulus

\section{Besar penurunan konsolidasi}

Dengan metode coefficient of compressibilty konsolidasi dapat dicari dengan rumus sebagai berikut:

$$
\mathrm{Sc}=\mathrm{M}_{\mathrm{v}} \Delta \sigma_{\mathrm{v}}, \mathrm{H}
$$

Dengan $\mathrm{m}_{\mathrm{v}}=$ Coefficient of compressibility, $\Delta \sigma_{\mathrm{v}}{ }^{\prime}=$ Perubahan tegangan efektif vertikal, $\mathrm{H}=$ Tebal lapisan 


\section{Koefisien konsolidasi vertical $\left(\mathrm{C}_{\mathrm{v}}\right)$}

Untuk menentukan kecepatan pengaliran air arah vertikal dalam tanah. metode yang dapat digunakan untuk menentukan koefisien konsolidasi yaitu parameter $\mathrm{C}_{\mathrm{v}}$ didapat dengan persamaan yaitu.

$$
C_{v}=\frac{T_{v} \cdot H_{d r}^{2}}{t}
$$

Dengan $\mathrm{H}_{\mathrm{dr}}=$ Panjang aliran rata-rata yang harus ditempuh air pori selama konsolidasi $(\mathrm{m}), \mathrm{H}=$ dikali 0.5 jika tanah lempung diantara tanah pasir, $\mathrm{H}=$ dikali 1 jika hanya ada satu lapisan pasir dan sebelah lain lapisan rapat air, $\mathrm{T}_{\mathrm{v}}=$ Faktor waktu, $\mathrm{t}=$ waktu konsolidasi (hari), $\mathrm{C}_{\mathrm{v}}=$ koefisien konsolidasi vertikal

\section{METODE PENELITIAN}

\section{Pengumpulan data}

Pada penelitian ini, data tanah yang akan digunakan berupa hasil uji CPTu di lapangan. Data mentah yang didapat dari hasil uji CPTu kemudian dimasukkan ke dalam program CPET-IT agar didapat parameter-parameter tanah lainnya yang dapat digunakan dalam perhitungan penurunan timbunan dengan menggunakan prefabricated vertical drain (PVD) atau tanpa PVD.

\section{Pengolahan data}

Pada proses pengolahan data, data-data yang telah dikumpulkan di teliti dan di analisis menggunakan program CPET-IT dengan memasukkan data hasil uji CPTu dilapangan sehingga didapat parameter-parameter dan jenis tanah yang diperlukan, yang kemudian dicari rata-rata dari parameter tanah tersebut yang akan diteruskan dengan melakukan analisis perhitungan besar penurununan dan lama waktu penurunan pada timbunan dengan menggunakan prefabricated vertical drain (PVD) dan tanpa PVD dengan bantuan program berbasis metode hingga.

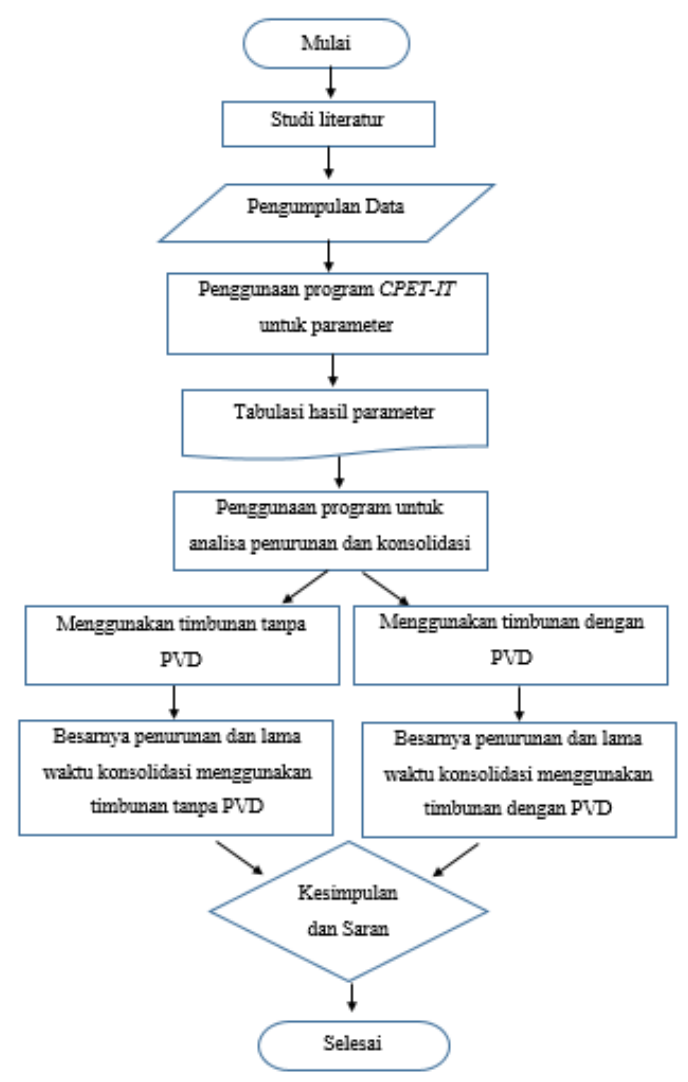

Gambar 2. Diagram alir metodologi penelitian 


\section{HASIL DAN PEMBAHASAN}

\section{Analisis menggunakan program CPET-IT}

Hasil analisis program CPET-IT yang berupa tegangan $(\sigma)$, coefficient of compressibility $\left(\mathrm{m}_{\mathrm{v}}\right)$, dan constrain modulus (M) kemudian dibandingkan dengan analisis manual.

Tabel 1. Hasil perbandingan coefficient of compressibilty $\left(\mathrm{m}_{\mathrm{v}}\right)$

\begin{tabular}{ccccccc}
\hline $\begin{array}{c}\text { Depth } \\
(\mathrm{m})\end{array}$ & $\begin{array}{c}\mathrm{K}_{\mathrm{sbt}} \\
(\mathrm{m} / \mathrm{s})\end{array}$ & $\begin{array}{c}\mathrm{C}_{\mathrm{v}} \\
\left(\mathrm{m}^{2} / \mathrm{s}\right)\end{array}$ & $\begin{array}{c}\gamma_{\text {water }} \\
\left(\mathrm{kN} / \mathrm{m}^{3}\right)\end{array}$ & $\begin{array}{c}\mathrm{m}_{\mathrm{v}} \\
\text { Manual } \\
(1 / \mathrm{MPa})\end{array}$ & $\begin{array}{c}\mathrm{m}_{\mathrm{v}} \\
\text { Program } \\
(1 / \mathrm{MPa})\end{array}$ & $\begin{array}{c}\text { Error } \\
(\%)\end{array}$ \\
\hline 0,50 & 0,00 & 6,08 & 9,81 & 0,01 & 0,01 & 0,00 \\
1,01 & 0,00 & 1,29 & 9,81 & 0,01 & 0,01 & 0,74 \\
1,50 & 0,00 & 0,00 & 9,81 & 0,02 & 0,02 & 0,01 \\
2,50 & 0,00 & 0,00 & 9,81 & 0,36 & 0,36 & 0,09 \\
3,50 & 0,00 & 0,00 & 9,81 & 0,07 & 0,07 & 0,11 \\
4,50 & 0,00 & 0,00 & 9,81 & 0,35 & 0,35 & 0,13 \\
5,50 & 0,00 & 0,00 & 9,81 & 0,47 & 0,47 & 0,06 \\
6,50 & 0,00 & 0,00 & 9,81 & 0,05 & 0,05 & 0,33 \\
7,50 & 0,00 & 0,00 & 9,81 & 0,12 & 0,12 & 0,04 \\
8,50 & 0,00 & 0,00 & 9,81 & 0,06 & 0,06 & 0,01 \\
9,50 & 0,00 & 0,00 & 9,81 & 0,40 & 0,40 & 0,10 \\
10,50 & 0,00 & 0,01 & 9,81 & 0,01 & 0,01 & 0,01 \\
10,93 & 0,00 & 0,00 & 9,81 & 0,00 & 0,00 & 0,00 \\
\hline
\end{tabular}

Dari hasil analisis diatas dengan menggunakan persamaan 1 didapat perbedaan hasil analisis menggunakan program dan manual yang kecil sehingga aplikasi pada program CPET-IT dapat digunakan.

Tabel 2. Hasil perbandingan constrain modulus (M)

\begin{tabular}{ccccc}
\hline $\begin{array}{c}\text { Depth } \\
(\mathrm{m})\end{array}$ & $\mathrm{m}_{\mathrm{v}}(1 / \mathrm{MPa})$ & $\begin{array}{c}\text { Constrained } \\
\text { Mod. } \\
\text { Manual } \\
(\mathrm{MPa})\end{array}$ & $\begin{array}{c}\text { Constrained } \\
\text { Mod. } \\
\text { Program } \\
(\mathrm{MPa})\end{array}$ & $\begin{array}{c}\text { Error } \\
(\%)\end{array}$ \\
\hline 0,5 & $1,15 \mathrm{E}-02$ & 87,330 & 87,330 & 0 \\
1,01 & 0,00852 & 117,393 & 117,393 & 0 \\
1,5 & 0,01791 & 55,822 & 55,822 & 0 \\
2,5 & 0,35799 & 2,793 & 2,793 & 0 \\
3,5 & 0,07455 & 13,414 & 13,414 & 0 \\
4,5 & 0,35495 & 2,817 & 2,817 & 0 \\
5,5 & 0,47013 & 2,127 & 2,127 & 0 \\
6,5 & 0,04884 & 20,475 & 20,475 & 0 \\
7,5 & 0,11884 & 8,415 & 8,415 & 0 \\
8,5 & 0,05975 & 16,737 & 16,737 & 0 \\
9,5 & 0,40375 & 2,477 & 2,477 & 0 \\
10,5 & 0,00596 & 167,685 & 167,685 & 0 \\
10,93 & 0,03545 & 28,208 & 28,208 & 0 \\
\hline
\end{tabular}

Dari hasil analisis diatas diatas dengan menggunakan persamaan 2 didapat perbedaan hasil analisis menggunakan program dan manual yang kecil sehingga aplikasi pada program CPET-IT dapat digunakan. 
Tabel 3. Hasil perbadingan tegangan $(\sigma)$

\begin{tabular}{cccccccc}
\hline $\begin{array}{c}\text { Depth } \\
(\mathrm{m})\end{array}$ & $\begin{array}{c}\gamma \\
\left(\mathrm{KN} / \mathrm{m}^{3}\right)\end{array}$ & $\begin{array}{c}\mathrm{u}_{0} \\
(\mathrm{kPa})\end{array}$ & $\begin{array}{c}\sigma_{\mathrm{v}} \\
\text { Manual } \\
(\mathrm{kPa})\end{array}$ & $\begin{array}{c}\sigma_{\mathrm{vo}}^{\prime} \\
\text { Manual } \\
(\mathrm{kPa})\end{array}$ & $\begin{array}{c}\sigma_{\mathrm{v}} \\
\text { Program } \\
(\mathrm{kPa})\end{array}$ & $\begin{array}{c}\sigma_{\mathrm{vo}}^{\prime} \\
\text { Program } \\
(\mathrm{kPa})\end{array}$ & $\begin{array}{c}\text { Error } \\
(\%)\end{array}$ \\
\hline 0,50 & 19,00 & 0,00 & 9,50 & 9,50 & 9,50 & 9,50 & 0,00 \\
1,01 & 19,00 & 0,00 & 19,19 & 19,19 & 19,19 & 19,19 & 0,00 \\
1,50 & 19,00 & 0,00 & 28,50 & 28,50 & 28,50 & 28,50 & 0,00 \\
2,50 & 19,00 & 0,00 & 47,50 & 47,50 & 47,50 & 47,50 & 0,00 \\
3,50 & 19,00 & 0,00 & 66,50 & 66,50 & 66,50 & 66,50 & 0,00 \\
4,50 & 19,00 & 4,91 & 85,50 & 80,60 & 85,50 & 80,60 & 0,00 \\
5,50 & 19,00 & 14,72 & 104,50 & 89,79 & 104,50 & 89,79 & 0,00 \\
6,50 & 19,00 & 24,53 & 123,50 & 98,98 & 123,50 & 98,98 & 0,00 \\
7,50 & 19,00 & 34,34 & 142,50 & 108,17 & 142,50 & 108,17 & 0,00 \\
8,50 & 19,00 & 44,15 & 161,50 & 117,36 & 161,50 & 117,36 & 0,00 \\
9,50 & 19,00 & 53,96 & 180,50 & 126,55 & 180,50 & 126,55 & 0,00 \\
10,50 & 19,00 & 63,77 & 199,50 & 135,74 & 199,50 & 135,74 & 0,00 \\
10,93 & 19,00 & 67,98 & 207,67 & 139,69 & 207,67 & 139,69 & 0,00 \\
\hline
\end{tabular}

Dari hasil analisis diatas didapat perbedaan hasil analisis menggunakan program dan manual yang kecil sehingga aplikasi pada program CPET-IT dapat digunakan.

\section{Parameter yang digunakan}

Parameter yang telah di anilisis menggunakan program CPET-IT kemudian dirata-ratakan dan menghasilkan parameter yang akan digunakan pada analisis penurunan pada timbunan.

Tabel 4. Parameter yang digunakan pada analisis penurunan

\begin{tabular}{ccccccccc}
\hline $\begin{array}{c}\text { Depth } \\
(\mathbf{m})\end{array}$ & Jenis tanah (SBT) & $\mathbf{m v}(\mathbf{1 / k P a})$ & $\begin{array}{c}\mathbf{M v u r} \\
(\mathbf{1} / \mathbf{k P a})\end{array}$ & $\begin{array}{c}\mathbf{M} \\
(\mathbf{k P a})\end{array}$ & $\begin{array}{c}\text { Mur } \\
(\mathbf{k P a})\end{array}$ & $\begin{array}{c}\mathbf{C v} \\
\left(\mathbf{m}^{2} / \mathbf{s}\right)\end{array}$ & $\begin{array}{c}\mathbf{C h} \\
\left(\mathbf{m}^{2} / \mathbf{s}\right)\end{array}$ & $\mathbf{C h} / \mathbf{C v}$ \\
\hline $0-5$ & SBT=3 (Clay to silty clay) & $1,97 \mathrm{E}-04$ & $3,94 \mathrm{E}-05$ & 17660 & 88300 & $9,55 \mathrm{E}-06$ & $1,52 \mathrm{E}-05$ & 1,59 \\
$5-7$ & SBT=4 (Clayey silt to silty clay) & $1,26 \mathrm{E}-04$ & $2,52 \mathrm{E}-05$ & 7950 & 39750 & $1,14 \mathrm{E}-06$ & $1,52 \mathrm{E}-05$ & 2,00 \\
$7-9$ & SBT=5 (silty sand to sandy silt) & $2,99 \mathrm{E}-05$ & $5,98 \mathrm{E}-06$ & 41950 & 209750 & $3,81 \mathrm{E}-05$ & $1,91 \mathrm{E}-05$ & 0,50 \\
$9-11$ & SBT=4 (Clayey silt to silty clay) & $7,17 \mathrm{E}-05$ & $1,43 \mathrm{E}-05$ & 17650 & 88250 & $6,06 \mathrm{E}-06$ & $1,91 \mathrm{E}-05$ & 3,15 \\
$11-13$ & SBT=4 (Clayey silt to silty clay) & $7,17 \mathrm{E}-05$ & $1,43 \mathrm{E}-05$ & 9710 & 48550 & $1,89 \mathrm{E}-06$ & $1,99 \mathrm{E}-06$ & 1,05 \\
$13-15$ & SBT=5 (silty sand to sandy silt) & $2,54 \mathrm{E}-05$ & $5,08 \mathrm{E}-06$ & 41960 & 209800 & $7,10 \mathrm{E}-05$ & $1,75 \mathrm{E}-04$ & 2,46 \\
$15-21$ & SBT=5 (silty sand to sandy silt) & $2,54 \mathrm{E}-05$ & $5,08 \mathrm{E}-06$ & 60650 & 303250 & $3,05 \mathrm{E}-04$ & $1,75 \mathrm{E}-04$ & 0,57 \\
\hline
\end{tabular}

Parameter hasil dari generelized data-data tanah yang dikumpulkan berdasarkan hasil uji CPTu dilapangan dan program CPET-IT. Yang kemudian digunakan dalam menghitung penurunan pada timbunan. 


\section{Analisis distribusi tegangan}

Tabel 5. Hasil analisis distribusi tegangan dengan bantuan program berbasis metode beda hingga

\begin{tabular}{crrc}
\hline Depth $(\mathrm{m})$ & Boussinesq & $\begin{array}{c}\text { multi } \\
\text { layer }\end{array}$ & westergard \\
\hline 0,00 & 94,96 & 98,87 & 91,43 \\
0,15 & 94,96 & 98,79 & 91,13 \\
1,20 & 94,88 & 98,22 & 89,02 \\
2,73 & 94,64 & 97,30 & 85,99 \\
3,25 & 94,06 & 95,91 & 82,21 \\
4,65 & 93,91 & 95,63 & 81,54 \\
5,00 & 93,44 & 94,78 & 79,61 \\
6,00 & 92,86 & 93,85 & 77,72 \\
7,00 & 92,18 & 92,84 & 75,85 \\
8,00 & 91,40 & 91,76 & 74,01 \\
9,00 & 90,52 & 90,61 & 72,20 \\
10,00 & 89,56 & 89,40 & 70,43 \\
11,00 & 88,53 & 88,14 & 68,70 \\
12,00 & 87,42 & 86,82 & 67,00 \\
13,00 & 86,26 & 85,47 & 65,34 \\
14,00 & 85,04 & 84,09 & 63,72 \\
15,00 & 82,75 & 81,55 & 60,90 \\
16,80 & 81,18 & 79,84 & 59,09 \\
18,00 & 79,58 & 78,11 & 57,34 \\
19,20 & 78,37 & 76,83 & 56,07 \\
20,10 & 77,15 & 75,54 & 54,83 \\
21,00 & 39,89 & 39,14 & 28,95 \\
\hline
\end{tabular}

Dari hasil analisis dengan bantuan program didapat perbedaan distribusi tegangan dengan berbagai metode dan metode boussinesq lah yang menghasilkan distribusi tegangan terbesar. Sehingga pada analisis penurunan pada timbunan digunakan distribusi tegangan dengan metode boussinesq.

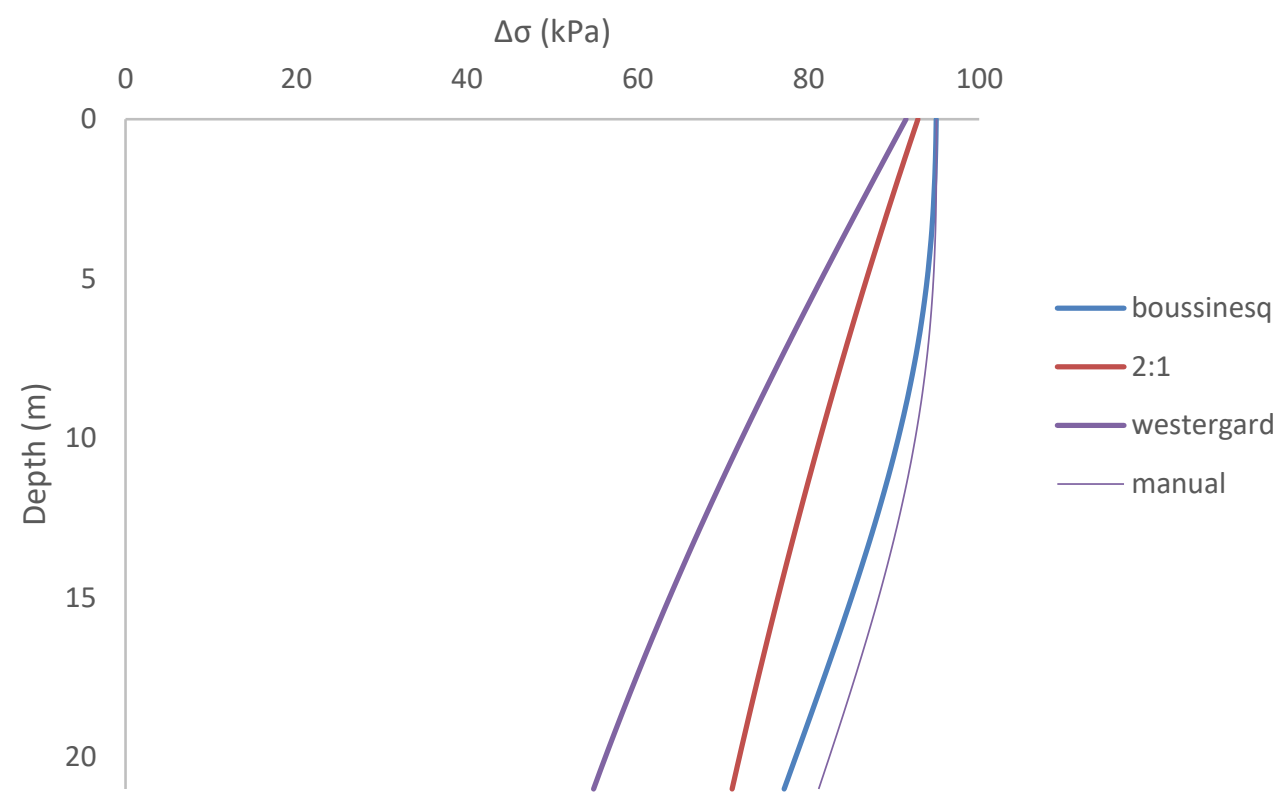

Gambar 3. Kurva hasil distribusi tegangan 


\section{Hasil analisis penurunan pada timbunanan}

Dalam menganalisis penurunan pada timbunan yang dibantu dengan program berbasis beda hingga, proses timbunan dibagi menjadi beberapa tahap yang dapat dilihat pada Tabel 6 dan Tabel 7.

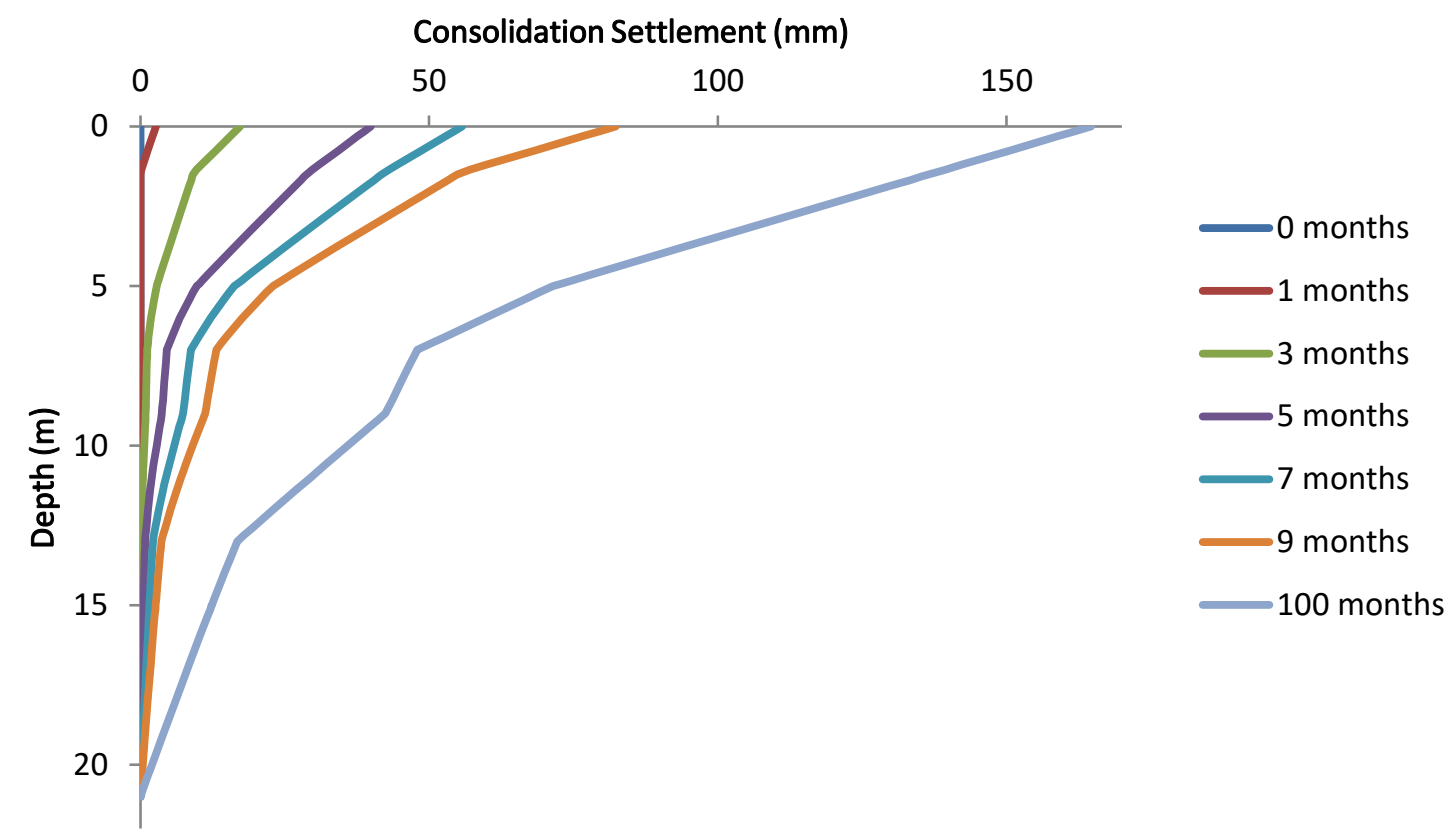

Gambar 4. Kurva hasil analisis penurunan konsolidasi tanpa prefabricated vertical drain (PVD)

Pada timbunan setinggi 5 meter yang di timbun secara bertahap dilakukan analisis penurunan konsolidasi pada timbunan tanpa menggunakan prefabricated vertical drain (PVD) dengan bantuan program berbasis metode beda hingga.

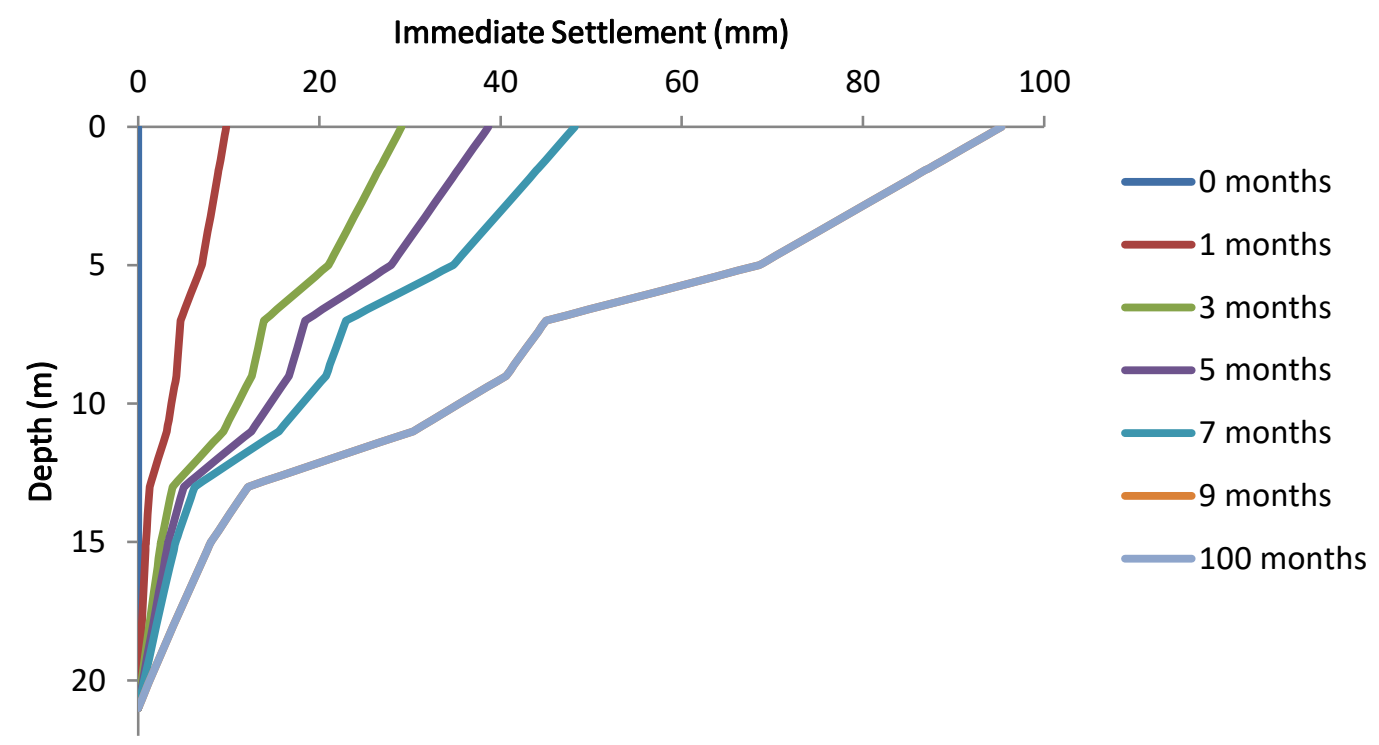

Gambar 5. Kurva hasil Analisis penurunan elastis tanpa prefabricated vertical drain (PVD)

Pada timbunan setinggi 5 meter yang di timbun secara bertahap dilakukan analisis penurunan seketika pada timbunan tanpa menggunakan prefabricated vertical drain (PVD) dengan bantuan program berbasis metode beda hingga. 


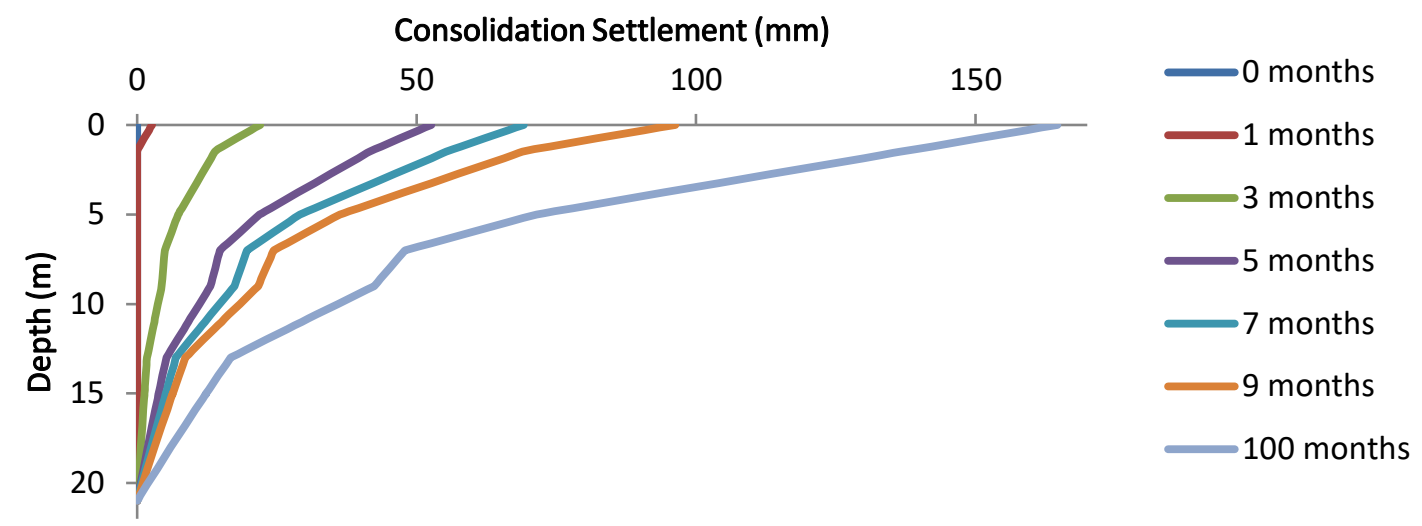

Gambar 6. Kurva hasil analisis penurunan konsolidasi dengan prefabricated vertical drain (PVD)

Pada timbunan setinggi 5 meter yang di timbun secara bertahap dilakukan analisis penurunan konsolidasi pada timbunan menggunakan prefabricated vertical drain (PVD) dengan bantuan program berbasis metode beda hingga.

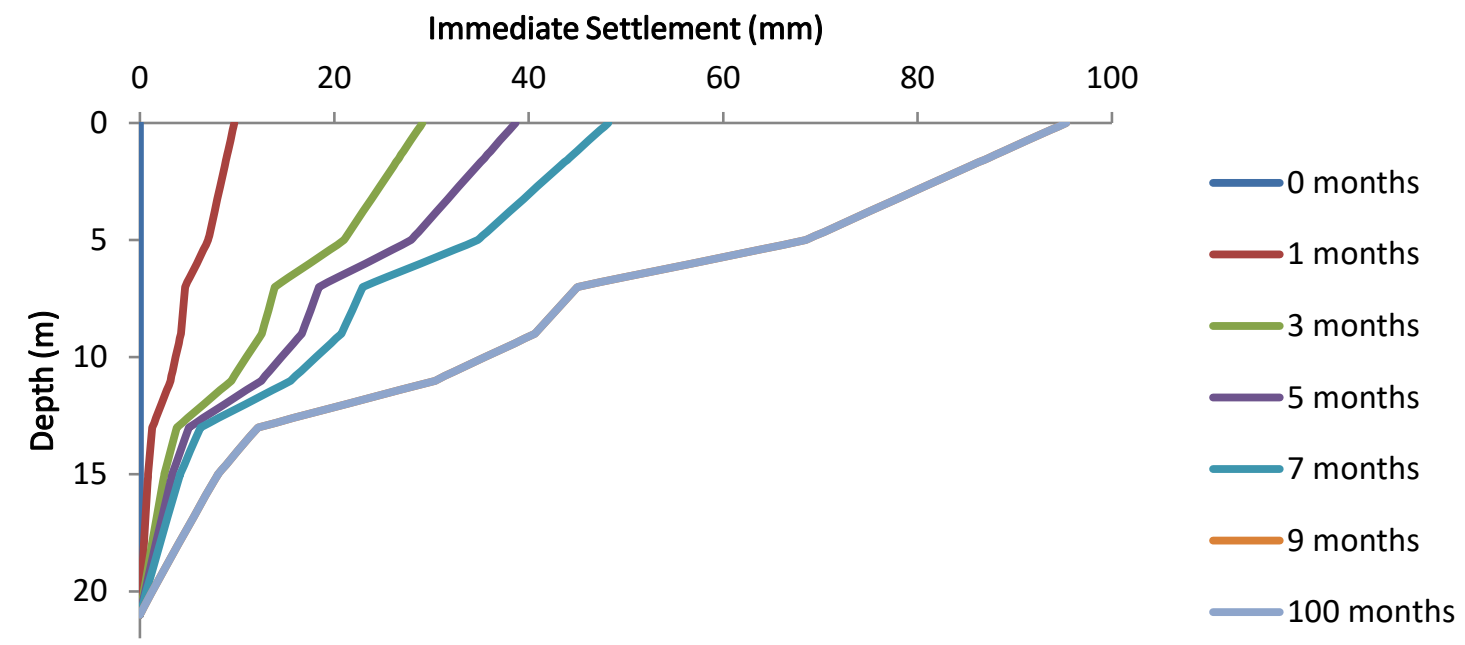

Gambar 7. Kurva hasil analisis penurunan elastis dengan prefabricated vertical drain (PVD)

Pada timbunan setinggi 5 meter yang di timbun secara bertahap dilakukan analisis penurunan seketika pada timbunan menggunakan prefabricated vertical drain (PVD) dengan bantuan program berbasis metode beda hingga.

\section{Waktu penurunan}

Tabel 6 Waktu konsolidasi pada timbunan tanpa menggunakan prefabricated vertical drain (PVD)

\begin{tabular}{cc}
\hline Stage $($ Tinggi timbunan) & Waktu \\
\hline Stage $1(0 \mathrm{~m})$ & 0 bulan \\
Stage $2(0,5 \mathrm{~m})$ & 7,77 bulan \\
Stage $3(1,5 \mathrm{~m})$ & 7,16 bulan \\
Stage $4(2 \mathrm{~m})$ & 5,91 bulan \\
Stage $5(2,5 \mathrm{~m})$ & 4,89 bulan \\
Stage $6(5 \mathrm{~m})$ & 5,72 bulan \\
\hline
\end{tabular}


Pada timbunan setinggi 5 meter yang di timbun secara bertahap dilakukan analisis waktu penurunan hingga mencapai konsolidasi $90 \%$ pada timbunan tanpa menggunakan prefabricated vertical drain (PVD) dengan bantuan program berbasis metode beda hingga.

Tabel 7 Waktu konsolidasi pada timbunan dengan menggunakan prefabricated vertical drain (PVD)

\begin{tabular}{cc}
\hline Stage (Tinggi timbunan) & Waktu \\
\hline Stage $1(0 \mathrm{~m})$ & 0 hari \\
Stage $2(0,5 \mathrm{~m})$ & 4,2 hari \\
Stage $3(1,5 \mathrm{~m})$ & 3 hari \\
Stage $4(2 \mathrm{~m})$ & 0,77 hari \\
Stage $5(2,5 \mathrm{~m})$ & 0,43 hari \\
Stage $6(5 \mathrm{~m})$ & 2,19 hari \\
\hline
\end{tabular}

Pada timbunan setinggi 5 meter yang di timbun secara bertahap dilakukan analisis waktu penurunan hingga mencapai konsolidasi $90 \%$ seketika pada timbunan menggunakan prefabricated vertical drain (PVD) dengan bantuan program berbasis metode beda hingga.

\section{Hubungan penurunan konsolidasi dan waktu}

Tabel 8. Hubungan penurunan konsolidasi dan waktu

\begin{tabular}{ccc}
\hline Time (month) & \multicolumn{2}{c}{ Settlement $(\mathrm{mm})$} \\
\cline { 2 - 3 } & Timbunan & Timbunan+PVD \\
\hline 0 & 0 & 0 \\
1 & 2,87 & 2,88 \\
3 & 17,66 & 22,45 \\
5 & 40,10 & 52,85 \\
7 & 55,90 & 69,38 \\
9 & 83,34 & 97,38 \\
9,68 & 120,50 & 164,65 \\
68,54 & 164,65 & 164,65 \\
100 & 164,65 & 164,65 \\
\hline
\end{tabular}

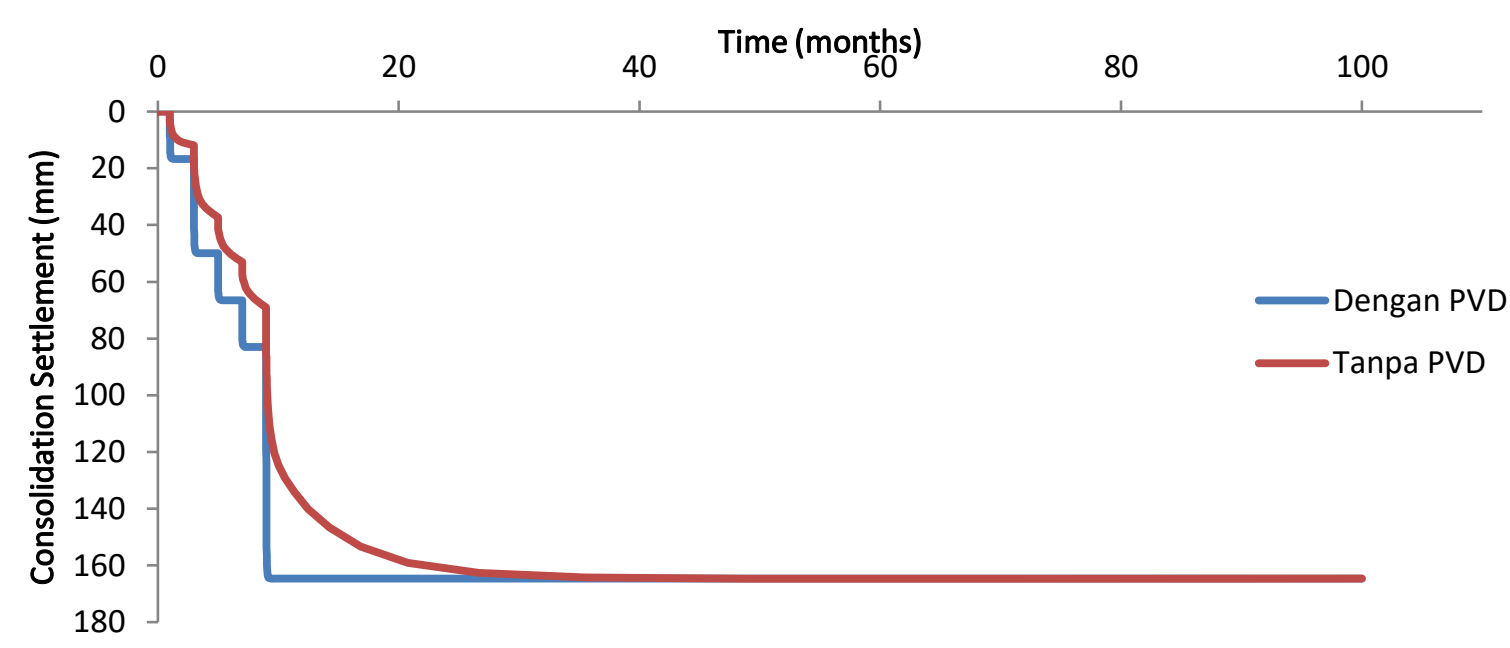

Gambar 8. Hubungan penurunan konsolidasi dan waktu

Dari hasil analisis dengan bantuan program berbasis metode beda hingga didapat beda waktu penurunan pada timbunan yang menggunakan PVD dan tanpa menggunakan PVD. Penurunan pada timbunan menggunakan PVD lebih cepat dikarenakan air terdisipasi secara arah vertikal dan horizontal sehingga timbunan dapat dengan ceppat mencapai konsolidasi final atau konsolidasi $90 \%$. 


\section{Perbandingan dengan hasil pengukuran di lapangan}

Dari hasil pengukuran dilapangan menggunakan uji settlement plate didapat hasil penurunan akhir selama 8 bulan dengan tinggi timbunan $5 \mathrm{~m}$ adalah sebesar $164 \mathrm{~mm}$.

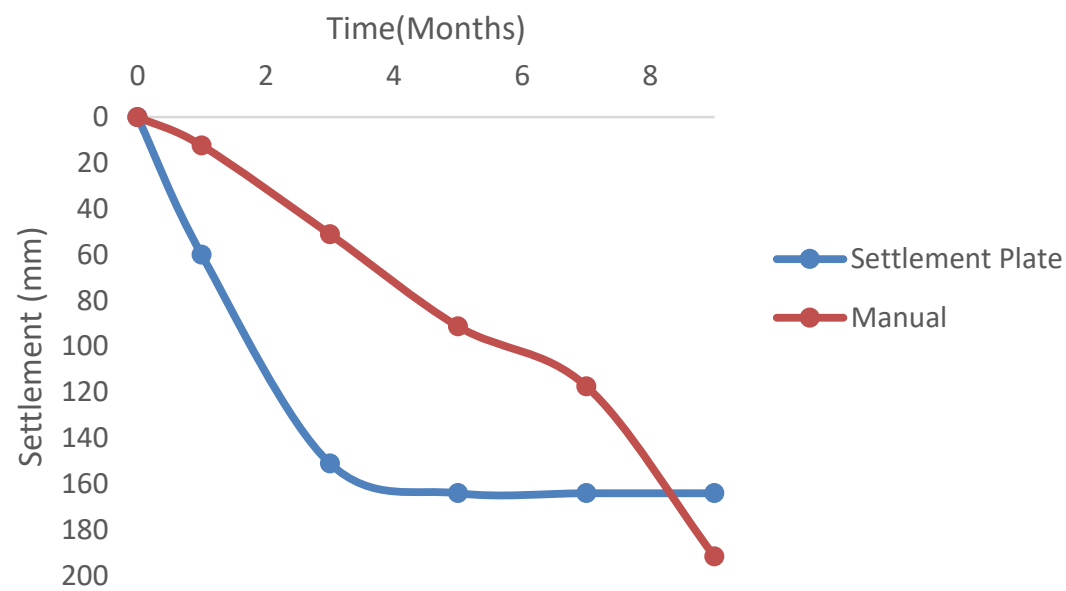

Gambar 9. Perbandingan dengan hasil uji settlement plate di lapangan

Hasil perbandingan total penurunan dengan metode analisis menggunakan program sebesar $191 \mathrm{~mm}$ dan hasil uji dilapangan sebesar $164 \mathrm{~mm}$ didapat perbedaan penurunan sebesar $16 \%$.

\section{KESIMPULAN DAN SARAN}

\section{Kesimpulan}

Berdasarkan hasil analisis dan pembahasan penurunan pada timbunan dengan prefabricated vertical drain (PVD) dapat mempercepat proses konsolidasi dari 68,54 bulan menjadi 9,68 bulan dengan efisiensi sebesar 85,70\% dan hasil penurunan total dari pengukuran di lapangan menggunakan uji settlement plate dibandingkan dengan hasil analisis menggunakan program berbasis metode beda hingga didapat perbedaan sebesar $16 \%$ dengan penurunan total pada uji settlement plate sebesar $164 \mathrm{~mm}$ dan metode analisis menggunakan program sebesar $191 \mathrm{~mm}$. Dikarenakan penurunan yang tidak begitu besar daat disimpulkan bahwa pada proyek ini tidak diperlukan penggunaan metode prefabricated vertical drain (PVD)

\section{Saran}

Dari hasil penelitian ini penulis memberikan beberapa saran untuk melengkapi kekurangan yang ada diantaranya adalah dengan melakukan perbandingan dengan hasil uji lapangan menggunakan metode lain da diperlukannya uji laboratorium agar didapat parameter tanah yang lebih spesifik, dan untuk analisis dapat dibandingkan menggunakan aplikasi lain, serta dapat melakukan analisis pada jenis tanah lain.

\section{DAFTAR PUSTAKA}

Dam, Loan T.K. et al. Vacuum Consolidation Method-Worldwide Practice and the Latest Improvement in Japan. Technical Research Report of Hazama Corporation, 2006.

Das, Braja M. Mekanika tanah (Prinsip-Prinsip Rekayaasa Geoteknisi) Jilid 1. Jakarta: Erlangga, 1995.

Mateos, Teresa. "Back analysis of a trial embankment settlement based on CPTu and oedometric test results". International Symposium on Ground Improvement IS-GI Brussels 31 May \& 1 June 2012, 2012, TC 211.

Pasaribu, T. H. dan Rudi Iskandar. "Analisa pada Penurunan Tanah Lunak Akibat Timbunan (Kasus Runway Bandara Medan Baru)". Jurnal Teknik Sipil USU, vol. 1, no. 2, 2012.

Rajesh, B. Giridhar, S. K. Chukka, dan A. Dey. "Finite Element Modeling of Embankment Resting on Soft Ground Stabilized with Prefabricated Vertical Drains". Geotechnical Engineering, vol. 49, no. 4, 2018, pp. 63-72.

Rocscience. Settle 3D-Settlement and consolidation analysist. Roscience Inc, 2007.

Mousavi, Seyedesmaeil dan Leong Sing Wong. "Compressibility characteristics of compacted clay treated with cement, peat ash and silica sand." Sains Malaysiana, vol. 46, no. 1, 2017, pp. 97-106.

T. Lunne, P.K. Robertson, dan J.J.M. Powel. Cone Penetration Testing. Blackie Academic and Professional, 1997. 
Widoanindyawati, Vemi, et al. "Analisa Efektifitas Kedalaman Pemasangan Pvd Studi Kasus Konstruksi Timbunan Apron Bandara Ahmad Yani Semarang". Seminar Nasional Sains dan Teknologi Universitas Muhammadiyah Jakarta 2016, 2016, pp. 1-11. 